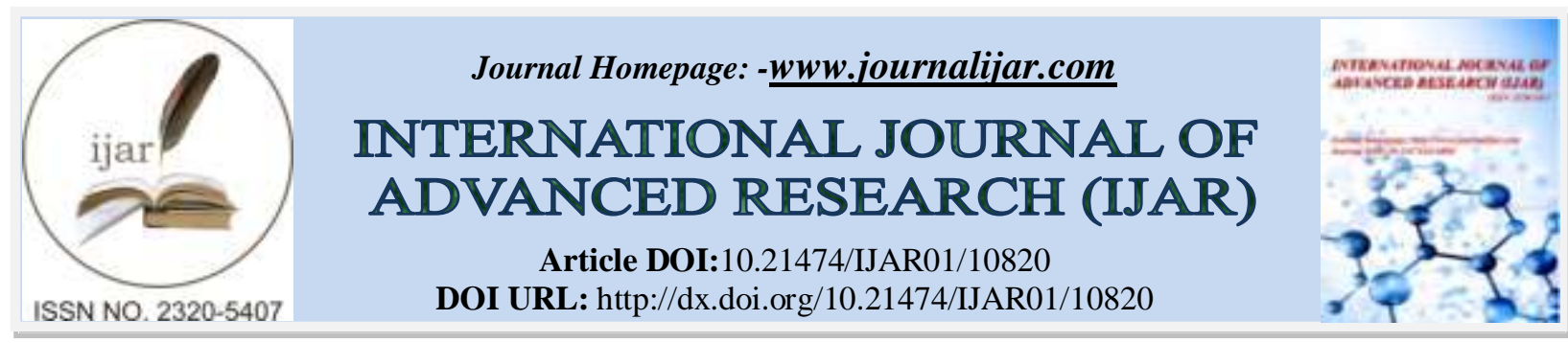

RESEARCH ARTICLE

\title{
NOVEL HPLC METHOD FOR DETERMINATION OF POLYPHENOLS IN AGRO-INDUSTRIAL WASTE OF DATE FRUITS
}

Jain Vandana Neeraj and Upadhye Kruttika Rajendra

Oriental College of Pharmacy, Sanpada, Navi Mumbai, 400705, India.

\section{Manuscript Info}

Manuscript History

Received: 12 February 2020

Final Accepted: 14 March 2020

Published: April 2020

Key words:-

Agro-Industrial Waste, Validation,

Phoenix Dactylifera, Hplc, Phenolic Acids

\begin{abstract}
Phoenix dactyliferais medicinally important plant. Fruits are traditionally used for nutritional purpose. Fruits and seeds are the rich sources of phenolic acids which exhibits strong antioxidant property. The aim of the work was to develop and validate a novel, simple method for quantification of gallic acid, protocatechuic acid, vanillic acid and syringic acid by High-Performance Liquid Chromatography (HPLC) in seeds of Phoenix dactylifera. The chromatographic analysis was performed on HPLC Shimadzu LC Prominence-i2030 model consisting of UV detector and auto sampler using Cosmosil C18 $(250 \times 4.6 \mathrm{~mm}, 5 \mu)$ column. The mobile phase used was $0.2 \%$ orthophosphoric acid: methanol (80:20). The hydroalcoholic extract was quantified by using HPLC-UV. The total run time was $30 \mathrm{~min}$ and retention time of gallic acid, protocatechuic acid, vanillic acid and syringic acid was found to be 4.8, 8.7, 20.2, $25.2 \mathrm{~min}$ respectively. The analytical method was validated according to ICH guidelines including parameters specificity, linearity and range, precision, accuracy, limit of detection (LOD), and limit of quantitation (LOQ).Phoenix dactylifera seeds are the rich source of phenolic acids which attribute to antioxidant properties of Phoenix dactylifera seeds. The seeds being agro-industrial waste of date fruits are cheaper source and can be used in medicinal and nutritional areas due to the presence of bioactive phytoconstituents.
\end{abstract}

\section{Introduction:-}

The palm date tree (Phoenix dactylifera) has played important role in providing valuable food for middle east and north Africa region. Date fruit is traditionally used for its nutritional and medicinal properties and it has been cultivated originally in Iran back to about 4000 B.C. North Africa, Egypt, Iran and Algeria are the top producer of date fruits throughout the world(VahidMohammadpourKarizaki, 2017; Ahmad Ateeq et al., 2013). Date fruit plays a major role in disease prevention through antioxidant, anti-inflammatory, and antibacterial activity(Milind Parle et al., 2010). Annually tons of date seeds are produced by date processing industries that contain valuable chemical constituents. The phytochemical study suggests the presence of phenolic acids, alkaloids, flavonoids, fatty acids, tocols and sterols(Renu Mishra et al., 2016). In ancient days date seeds were applied to wounds, lesions, inflammation, and used as expectorant and laxative(Ahmad Ateeq et al., 2013).Date seeds are also used for the production of energy/fuel by combustion or pyrolysis and generation of bioethanol(Mohammad Uzzal Hossain Jaordder, et al., 2015).In the present study, we have developed a novel HPLC method for simultaneous estimation of 
four important polyphenol compounds, namely gallic acid, protocatechuic acid, vanillic acid and, syringic acid in date seeds.

Phenolic compounds are multipurpose bioactive agents present in various plant parts and these compounds exhibit an important role as antioxidants. In recent years, the focus on natural antioxidants increased all over the world to replace synthetic antioxidants because of their unwanted effects on human health. Gallic acid is well known for its antioxidative, anti-aging, anticarcinogenic, antiallergic, anti-inflammatory, antiviral, and antibacterial and antiarteriosclerosis activities(Sneha Choubey et al., 2015).Protocatechuic acid is structurally similar to the gallic acid, it has anti-aging, antiulcer, anticancer, antifibrotic, atherosclerotic, antibacterial, antiviral properties(Sahil Kakkar et al., 2014). Vanillic acid and syringic acid are reported to suppress the liver inflammation and shows hepatoprotective activity, syringic acid is also evaluated for its antidiuretic activity(Ayano Itoh et al., 2009; Jayachandran Muthukumaran et al., 2013). These important phenolic acids attributes to the pharmacological properties of dates. In this study, we have tried to valorize agro-industrial waste by developing simple, isocratic HPLC method for simultaneous estimation of gallic acid, protocatechuic acid, vanillic acid and syringic acid in date seeds.

The literature survey revealed that so far date seeds has been studied quantitatively only for their fixed oil composition(Golshan Tafti, et al., 2016; ImeddedineNehdi, 2010), hence the present study aims to quantify phenolic compounds from Phoenix dactylifera seeds by using HPLC-UV. This is the first report for quantitative estimation of gallic acid, protocatechuic acid, vanillic acid and syringic acid in the date seeds.

\section{Experimental: Instrument:}

Instrument employed in this study was RP-HPLC Shimadzu LC Prominence-i2030 model consisting of UV detector and an auto sampler. Software used was lab solution. Cosmosil C18 $(250 \times 4.6 \mathrm{~mm}, 5 \mu)$ column was used for analysis. The mobile phase used was $0.2 \%$ ortho-phosphoric acid: methanol (80:20), the flow rate was $1.0 \mathrm{~mL} / \mathrm{min}$ and the injection volume was kept $10 \mu \mathrm{L}$. The column temperature was set at $28^{\circ} \mathrm{C}$ and gallic acid, protocatechuic acid, vanillic acid and syringic acid were detected at $270 \mathrm{~nm}$.

\section{Chemicals, reagent and standards:}

Methanol and ortho-phosphoric acid were HPLC grade and purchased from Thermo Fisher Scientific, India Pvt. Ltd. Mumbai. All standards of purity more than $95 \%$ were procured from Chemdyes Corporation, Rajkot, India.

\section{Plant material:}

The date fruits were procured from market, seeds were separated and dried. The dried seeds were powdered using pulverizer.

\section{Preparation of sample extract:}

The reflux method was used to obtain the hydroalcohol extract of date seed powder. Five grams of date seed powder was refluxed with $70 \mathrm{~mL}$ hydroalcohol for $20 \mathrm{~min}$ using reflux assembly. The solution was filtered through Whatman filter paper to get a clear solution and the volume was made up to $100 \mathrm{~mL}$. The final solution obtained was used for analysis.

\section{Preparation of standards:}

$100 \mathrm{mg}$ of gallic acid, protocatechuic acid, vanillic acid and syringic acid were accurately weighed and transferred into $100 \mathrm{~mL}$ volumetric flasks separately and volume was made up to $100 \mathrm{~mL}$ with HPLC grade methanol. The stock solution was suitably diluted for HPLC injection.

\section{Method Development:}

Wavelength selected for detection was $270 \mathrm{~nm}$ for the analysis of gallic acid, protocatechuic acid, vanillic acid and syringic acid. To obtain proper resolution of gallic acid, protocatechuic acid, vanillic acid and syringic acid, several modifications were tried in mobile phase composition such as acids used in aqueous phase, change in $\mathrm{pH}$, and change in flow rate. When methanol and water (45:55) was used as mobile phase, the asymmetry of peak in the mixed standard solution was more. When methanol and $0.1 \%$ acetic acid $(25: 75)$ was used as the mobile phase, the peaks were resolved properly in mixed standards, but not in the sample solution(Fig.1 and 2). Finally the proper resolution of the selected compounds was obtained using $0.2 \%$ ortho-phosphoric acid: methanol (80:20) as the mobile phase (Fig.3 and 4). The optimized chromatographic conditions are givenbelow(Table 1). 


\section{Results and Discussion:- \\ Method validation:}

The developed method was validated as per ICH guidelines Q2 (R1) which include the parameters such as specificity, linearity and range, accuracy, precision, Limit of detection (LOD), Limit of quantification (LOQ) and robustness.

\section{Specificity:}

It is performed to ensure the identification, purity testing, and quantification of a marker compound from the seed powder under analysis. Specificity was confirmed by comparing the retention time and UV spectra of the standards.

\section{Linearity and range:}

The area under curve data versus the concentration of gallic acid, protocatechuic acid, vanillic acid and syringic acid were treated by linear correlation coefficient. The calibration curve equation for gallic acid, protocatechuic acid, vanillic acid and syringic acid were obtained as $y=42347 x+48475\left(R^{2}=0.992\right), y=50276 x+97274\left(R^{2}=0.997\right)$, $\mathrm{y}=75768 \mathrm{x}+11155\left(\mathrm{R}^{2}=0.992\right)$ and, $\mathrm{y}=41501 \mathrm{x}+15531\left(\mathrm{R}^{2}=0.997\right)$ respectively. This method was found to be linear in the range of $0.5-20 \mu \mathrm{g} / \mathrm{mL}$ for all the marker compounds The linearity results are shown below (Table 2) and linearity graphs of all standards are presented below(Fig.5-Fig.8). The high value of R2 > 0.99 in the tested range of $0.5-20 \mu \mathrm{g} / \mathrm{mL}$ concentrations is indicative of responsive linearity.

\section{Quantification of markers in date seeds:}

Quantification of the selected markers was done by performing HPLC analysis of sample solution. The amount of gallic acid, protocatechuic acid, vanillic acid and syringic acid present in the date seed extract was calculated using linear regression analysis (Table 3).The obtained results were used for further recovery studies.

\section{Accuracy:}

Accuracy of the method was determined by the \% mean recovery of each compound in the formulation at three distinct levels $(80 \%, 100 \%$ and $120 \%)$. At each level, three determinations were performed (Table 4). The accepted limits of mean recovery are 98-102\% and all observed data were within the range, which specifies good recovery values, supporting the accuracy of the method developed. The mean \% recovery was found to be within the range.

\section{Precision:}

For the determination of system precision and method precision, six replicate injections of standard and sample were injected respectively. The precision was represented as percent relative standard deviation (\% RSD) of the response. (Table 5 and 6). The statistical analysis of the results proved that $\%$ RSD of the peak areas obtained was < 2.

\section{Limit of detection (LOD):}

LOD was calculated by formula

$\mathrm{LOD}=3.3 \sigma / \mathrm{S}$

Where, $\sigma=$ standard deviation of intercepts of the calibration curve and $\mathrm{S}$ is the Slope of the calibration curve. The LOD of gallic acid, protocatechuic acid, vanillic acid and syringic acid was found to be $0.309,0.376,0.213$ and $0.388 \mu \mathrm{g} / \mathrm{mL}$ respectively.

\section{Limit of quantification (LOQ):}

LOQ was calculated by formula

$\mathrm{LOQ}=10 \sigma / \mathrm{S}$.

LOQ of gallic acid, protocatechuic acid, vanillic acid and syringic acid was found to be $0.937 \mu \mathrm{g} / \mathrm{ml}, 1.141 \mu \mathrm{g} / \mathrm{ml}$, $0.645 \mu \mathrm{g} / \mathrm{ml}$ and $1.174 \mu \mathrm{g} / \mathrm{ml}$ respectively.

\section{Robustness:}

Robustness of analytical method was assessed by deliberate changes in the mobile phase flow rate $( \pm 0.1 \mathrm{~mL} / \mathrm{min})$, column temperature $\left( \pm 1^{\circ} \mathrm{C}\right)$, Wavelength $( \pm 1 \mathrm{~nm})$ as shown in the Table 7.To assure robustness of method, each marker was evaluated in triplicate. 


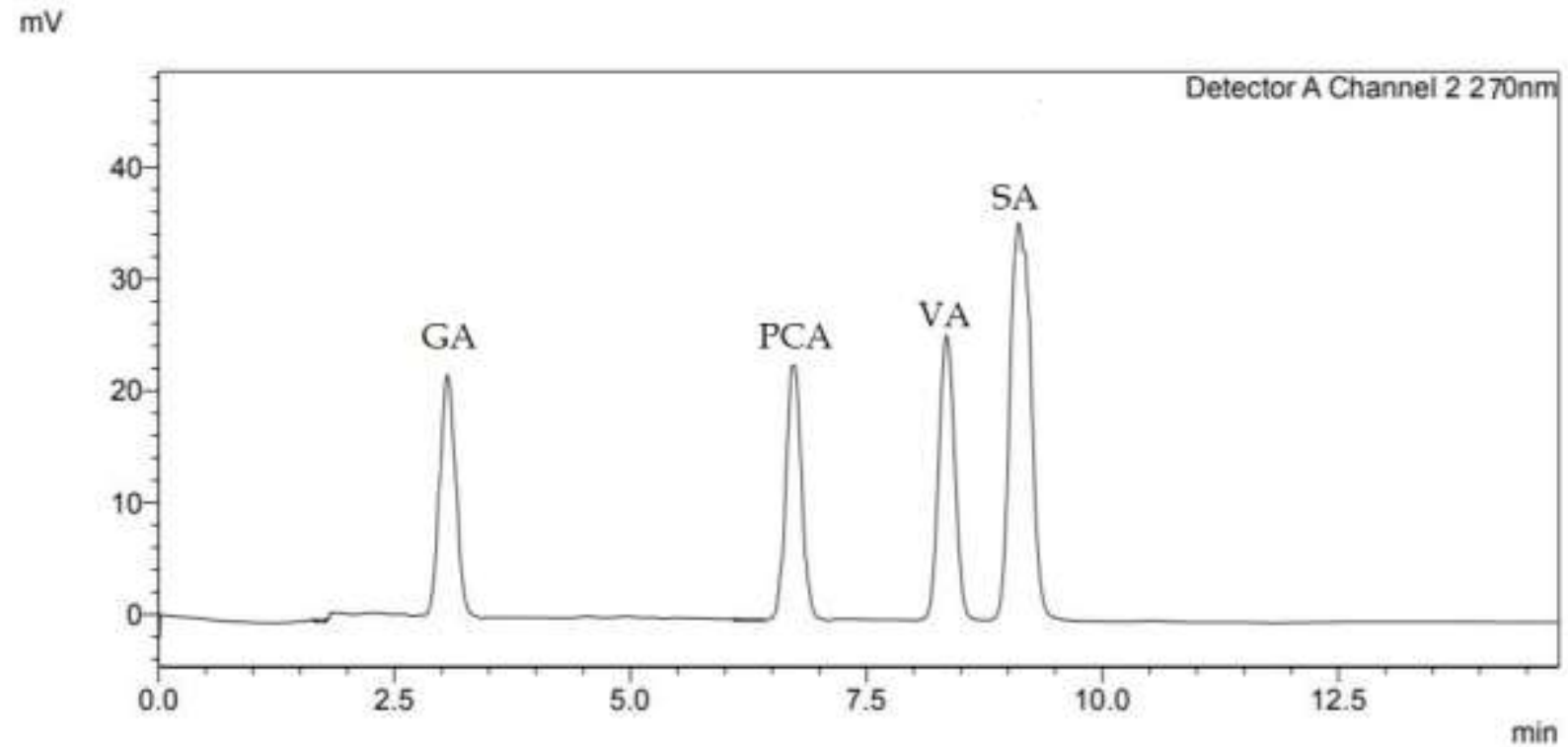

Figure 1:- Trial chromatogram of mixed standards in mobile phase methanol: $0.1 \%$ acetic acid(25:75).

$\mathrm{mV}$

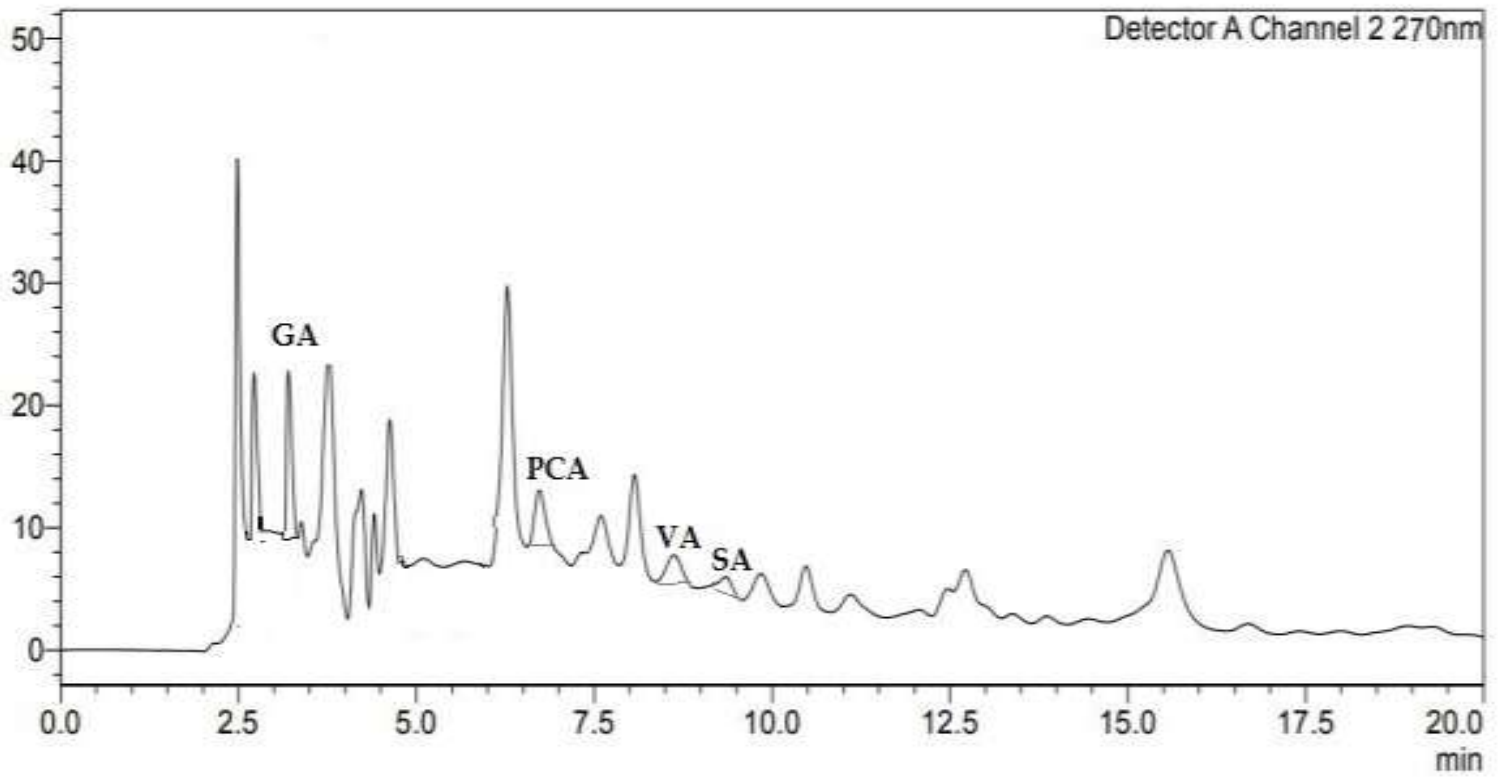

Figure 2:- Trial chromatogram of sample in mobile phase methanol: 0.1\% acetic acid(25:75). 
$\mathrm{mV}$

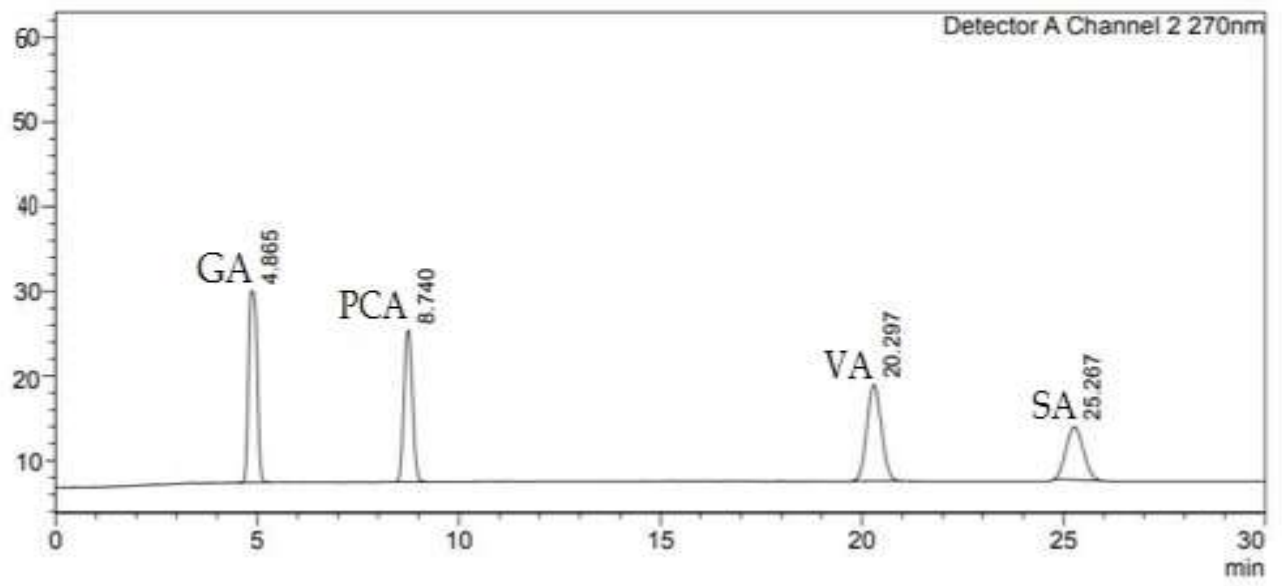

Figure 3:- Chromatogram of mixed standards.

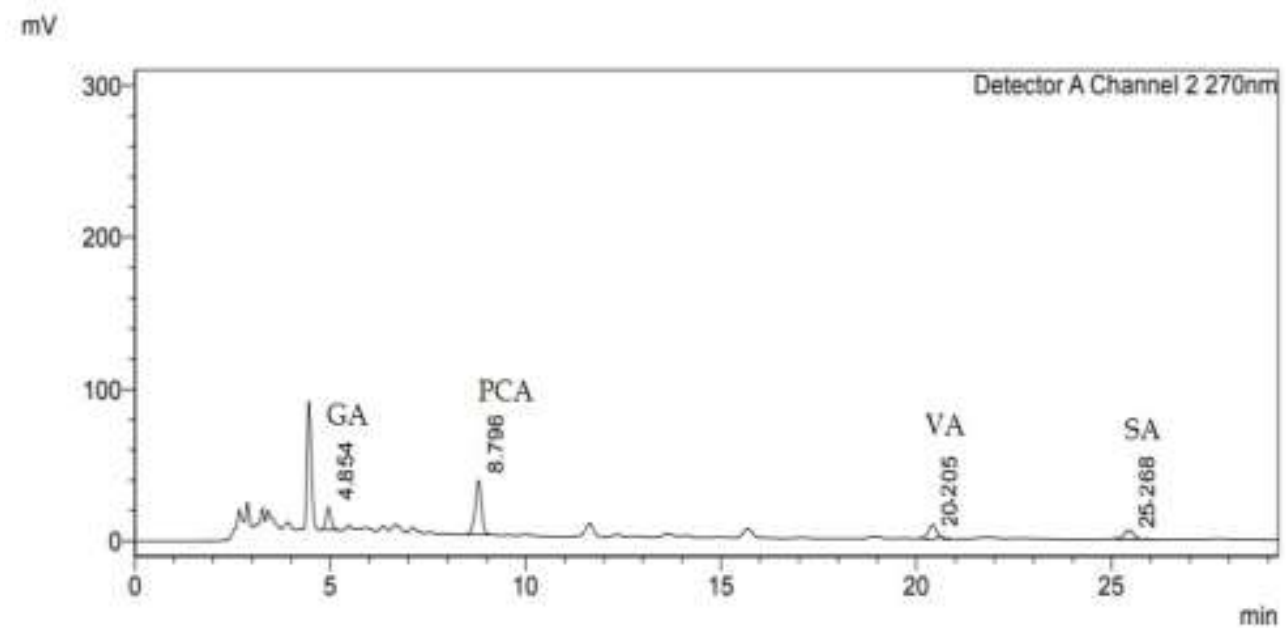

Figure 4:- Chromatogram of date seed sample.

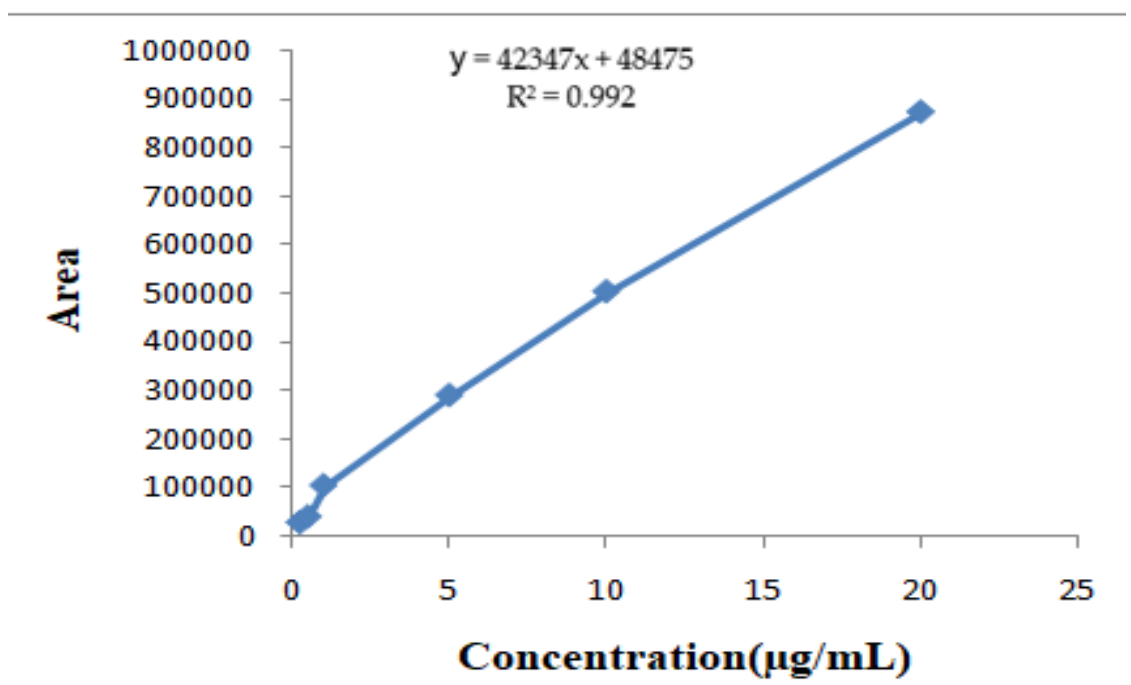

Figure 5:- Calibration curve of gallic acid 


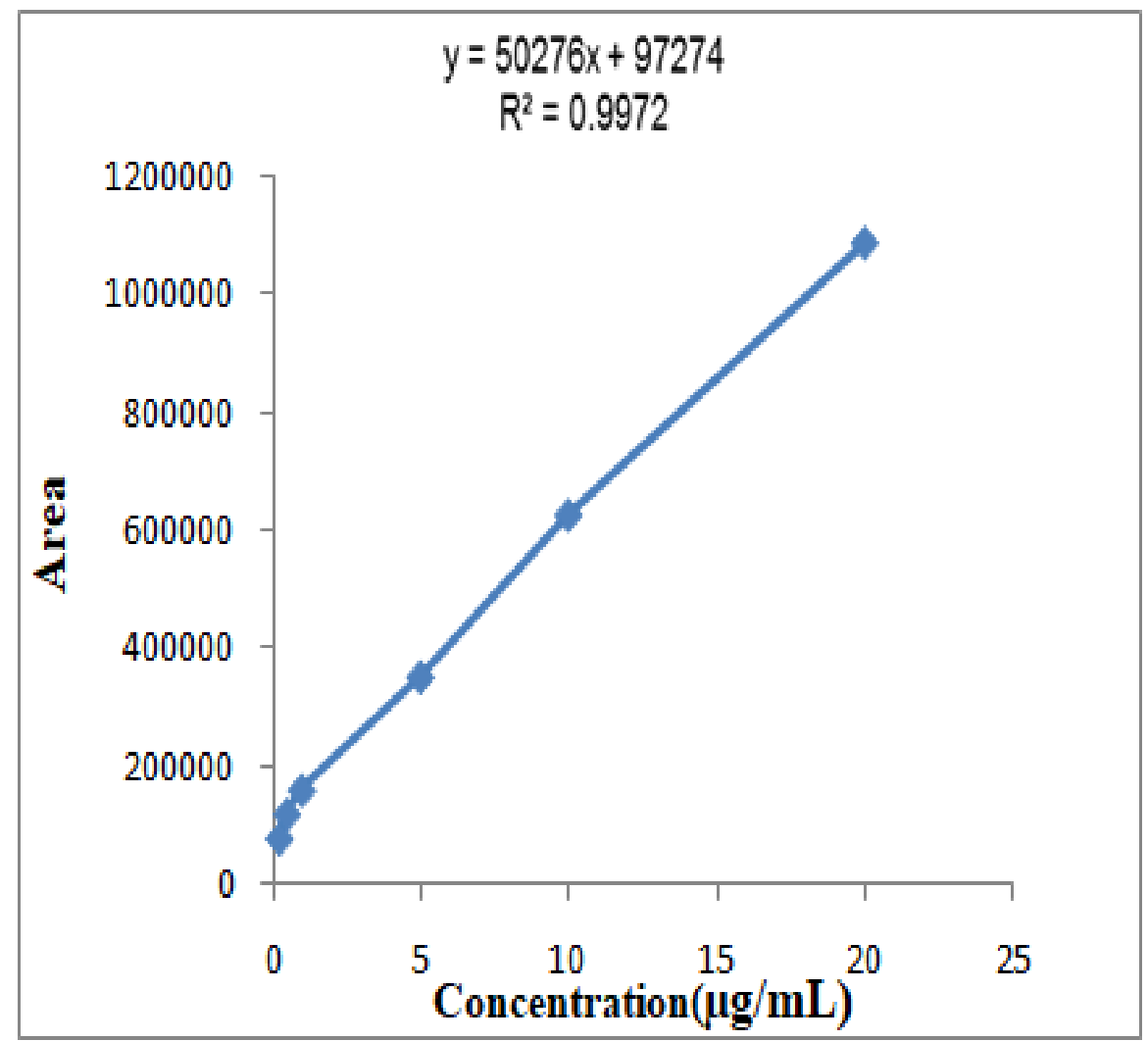

Figure 6:- Calibration curve of protocatechuic acid.

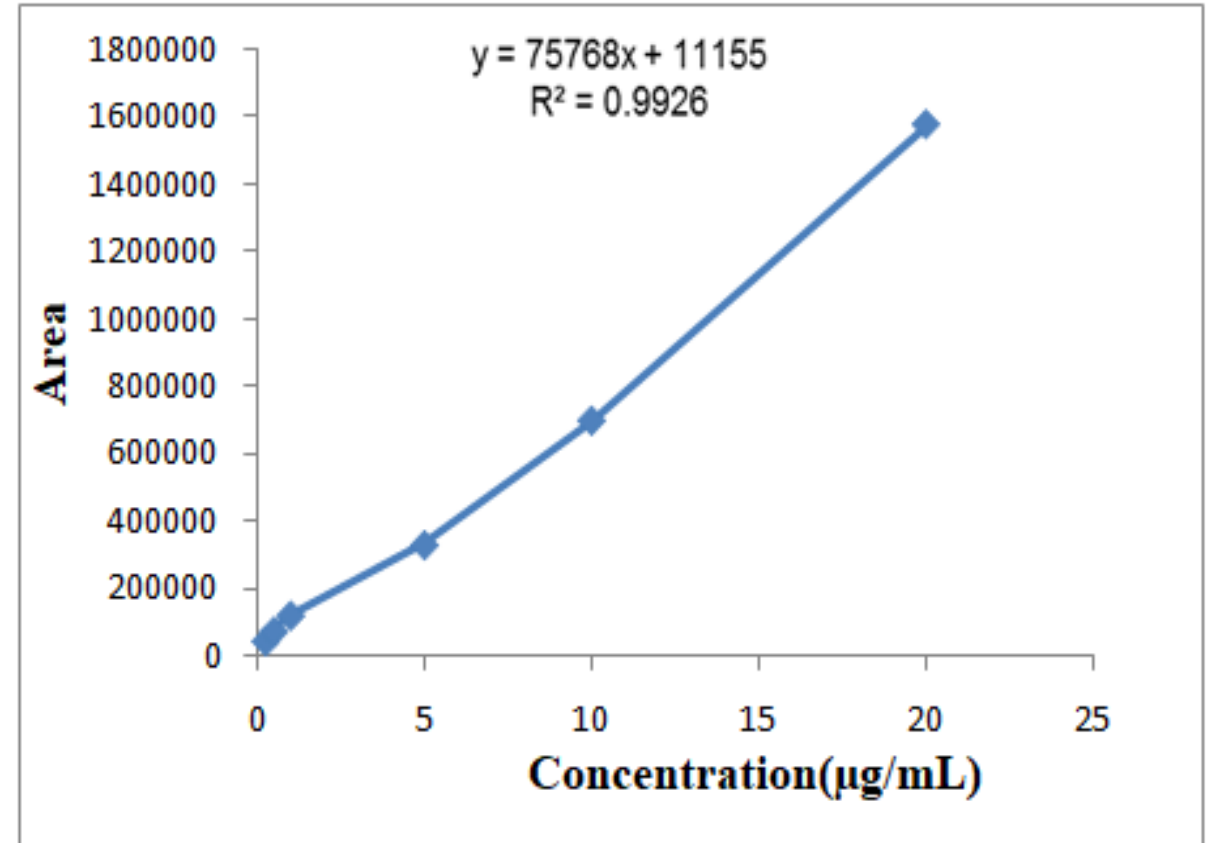

Figure7:- Calibration curve of vanillic acid. 


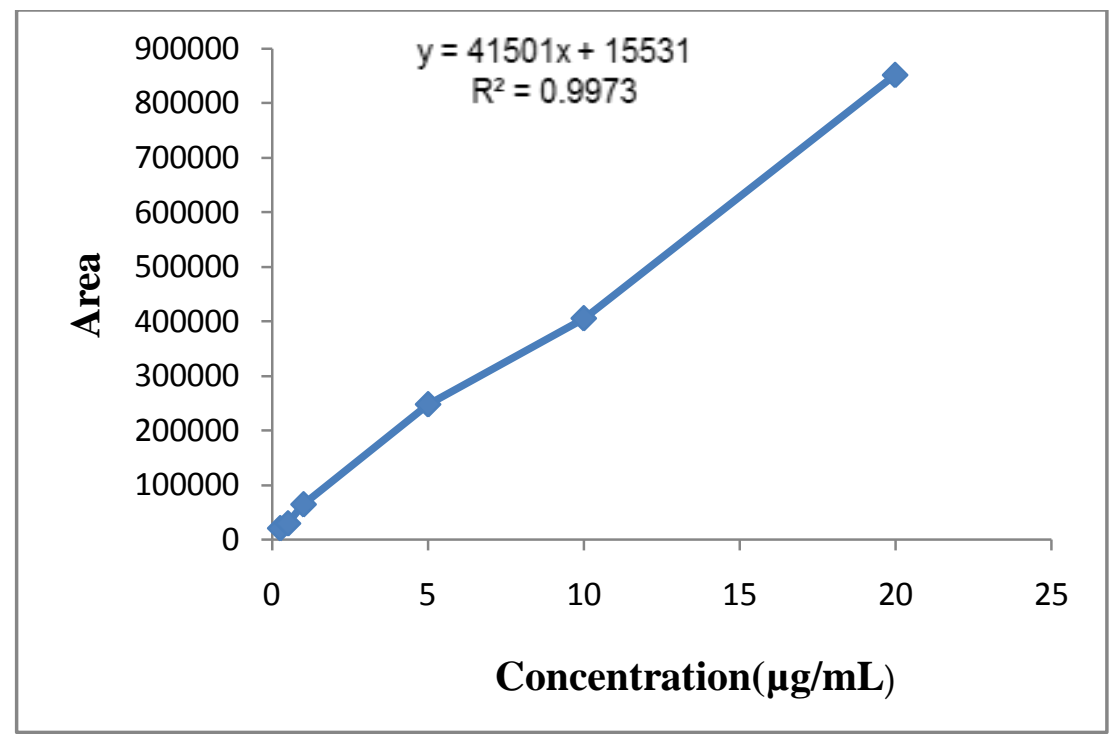

Figure 8:- Calibration curve of syringic acid.

Table 1:- The optimized chromatographic conditions.

\begin{tabular}{|l|l|}
\hline Separation variables & Optimized conditions \\
\hline Chromatography & RP-HPLC Shimadzu LC Prominence-i2030 \\
\hline Column & Cosmosil C18 \\
\hline Mobile phase & $0.2 \%$ ortho- phosphoric acid: methanol (80:20) \\
\hline Flow rate & $1 \mathrm{~mL} / \mathrm{min}$ \\
\hline Total Run time & $30 \mathrm{~min}$ \\
\hline Temperature & $28^{\circ} \mathrm{C}$ \\
\hline Detection wavelength & $270 \mathrm{~nm}$ \\
\hline Retention time of gallic acid & $4.8 \mathrm{~min}$ \\
\hline Retention time of protocatechuic acid & $8.7 \mathrm{~min}$ \\
\hline Retention time of vanillic acid & $20.2 \mathrm{~min}$ \\
\hline Retention time of syringic acid & $25.2 \mathrm{~min}$ \\
\hline
\end{tabular}

Table 2:- Linear regression data obtained from calibration curves of gallic acid, protocatechuic acid, vanillic acid and syringic acid.

\begin{tabular}{|r|r|r|r|r|}
\hline Parameters & Gallic acid & Protocatechuic acid & Vanillic acid & Syringic acid \\
\hline $\begin{array}{r}\text { Linearity range } \\
(\mu \mathrm{g} / \mathrm{mL})\end{array}$ & $0.5-20$ & $0.5-20$ & $0.5-20$ & $0.5-20$ \\
& & & & \\
\hline $\begin{array}{r}\text { Equation of } \\
\text { regression line }\end{array}$ & $\mathrm{y}=42347 \mathrm{x}+48475$ & $\mathrm{y}=50276 \mathrm{x}+97274$ & $\mathrm{y}=75768 \mathrm{x}+11155$ & $\mathrm{y}=41501 \mathrm{x}+15531$ \\
\hline $\mathrm{R}^{2}$ & & & 0.992 & 0.997 \\
\hline Slope & 0.992 & 0.997 & 75768 & 41501 \\
\hline Intercept & 42347 & 50276 & 11155 & 15531 \\
\hline
\end{tabular}

Table 3:- Analysis of standards in sample.

\begin{tabular}{|l|l|}
\hline Standards & \% w/w content \\
\hline Gallic acid & 0.0018 \\
\hline Protocatechuic acid & 0.0059 \\
\hline Vanillic acid & 0.0054 \\
\hline Syringic acid & 0.0010 \\
\hline
\end{tabular}

Table 4:- \% Recovery results for gallic acid, protocatechuic acid, vanillic acid and syringic acid.

\begin{tabular}{|l|l|l|l|l|l|l|l|}
\hline Compounds & Level $(\%)$ & Sample & Standard & Total & Area & Amount & $\%$ \\
\hline
\end{tabular}




\begin{tabular}{|l|l|l|l|l|l|l|l|}
\hline & & $(\boldsymbol{\mu g})$ & $\begin{array}{l}\text { added } \\
(\mathbf{\mu g})\end{array}$ & $\begin{array}{l}\text { amount } \\
(\boldsymbol{\mu g})\end{array}$ & $(\mathbf{n}=\mathbf{3})^{*}$ & recovered( $\boldsymbol{\mu g})$ & Recovery \\
\hline \multirow{5}{*}{ Gallic acid } & 80 & 1.9 & 1.5 & 3.4 & 189913.9 & 3.37 & 99.3 \\
\cline { 2 - 7 } & 100 & 1.9 & 1.9 & 3.8 & 205158.9 & 3.70 & 98.9 \\
\cline { 2 - 7 } & 120 & 1.9 & 2.2 & 4.1 & 138250.6 & 4.10 & 100.2 \\
\hline \multirow{3}{*}{$\begin{array}{l}\text { Protocatechuic } \\
\text { acid }\end{array}$} & 80 & 5.9 & 4.8 & 10.7 & 633718.9 & 10.63 & 99.4 \\
\cline { 2 - 7 } & 100 & 5.9 & 5.9 & 11.8 & 694552.8 & 11.75 & 99.6 \\
\cline { 2 - 7 } & 120 & 5.9 & 7.2 & 13.1 & 763933.7 & 13.24 & 101.1 \\
\hline Vanillic acid & 80 & 0.5 & 0.4 & 0.9 & 84649.9 & 0.88 & 98 \\
\cline { 2 - 7 } & 100 & 0.5 & 0.5 & 1 & 93742.1 & 0.99 & 99 \\
\cline { 2 - 7 } & 120 & 0.5 & 0.6 & 1.1 & 102076.6 & 1.10 & 100.2 \\
\hline Syringic acid & 80 & 1 & 0.8 & 1.8 & 91062.8 & 1.78 & 98.88 \\
\cline { 2 - 7 } & 100 & 1 & 1 & 2 & 99114 & 1.97 & 98.53 \\
\cline { 2 - 7 } & 120 & 1 & 1.2 & 2.2 & 108078.2 & 2.18 & 99.3 \\
\hline
\end{tabular}

*n - Number of injections

Table 5:- System precision results.

\begin{tabular}{|l|l|l|l|l|}
\hline S.No. & $\begin{array}{l}\text { peak area of Gallic } \\
\text { acid(5 } \mathbf{\mu g})\end{array}$ & $\begin{array}{l}\text { peak area of } \\
\text { Protocatechuic acid } \\
(\mathbf{5} \boldsymbol{\mu g})\end{array}$ & $\begin{array}{l}\text { peak area of Vanillic } \\
\text { acid } \mathbf{5} \boldsymbol{\mu g})\end{array}$ & $\begin{array}{l}\text { peak area of Syringic } \\
\text { acid }(\mathbf{5} \boldsymbol{\mu g})\end{array}$ \\
\hline 1 & 291408 & 353068 & 331479 & 249458 \\
\hline 2 & 300148 & 352243 & 341484 & 245616 \\
\hline 3 & 297372 & 367140 & 336439 & 252377 \\
\hline 4 & 298348 & 352251 & 331448 & 252377 \\
\hline 5 & 296142 & 356912 & 343155 & 242261 \\
\hline 6 & 290172 & 354363 & 336484 & 240337 \\
\hline Mean \pm S.D. & $295598 \pm 3968$ & $355996 \pm 5734$ & $336748 \pm 4889$ & $245194 \pm 4874$ \\
\hline$\%$ RSD & 1.34 & 1.61 & 1.45 & 1.99 \\
\hline
\end{tabular}

*S.D.- Standard deviation, *\% RSD - relative standard deviation

Table 6:- Method precision result.

\begin{tabular}{|l|l|l|l|l|}
\hline S.No. & $\begin{array}{l}\text { peak area of gallic } \\
\text { acid }\end{array}$ & $\begin{array}{l}\text { peak area of } \\
\text { protocatechuic acid }\end{array}$ & $\begin{array}{l}\text { peak area of vanillic } \\
\text { acid }\end{array}$ & $\begin{array}{l}\text { peak area of syringic } \\
\text { acid }\end{array}$ \\
\hline 1 & 127829 & 397169 & 52572 & 57933 \\
\hline 2 & 129393 & 384755 & 52345 & 57566 \\
\hline 3 & 125597 & 385769 & 53278 & 56129 \\
\hline 4 & 128663 & 385536 & 52154 & 58145 \\
\hline 5 & 127293 & 376533 & 53465 & 56784 \\
\hline 6 & 125672 & 376533 & 53545 & 57845 \\
\hline Mean \pm SD & $127408 \pm 1549$ & $384383 \pm 7617$ & $52893 \pm 608$ & $57400 \pm 782$ \\
\hline \% RSD & 1.22 & 1.98 & 1.15 & 1.36 \\
\hline
\end{tabular}

*S.D. - Standard deviation,* \%RSD - relative standard deviation

Table 7:- Robustness result of gallic acid, protocatechuic acid, vanillic acid and syringic acid.

\begin{tabular}{|l|l|l|l|l|l|l|}
\hline \multirow{2}{*}{ Parameters } & \multicolumn{3}{|c|}{ Gallic acid } & $\begin{array}{l}\text { Protocatechuic } \\
\text { acid }\end{array}$ & Vanillic acid & \multirow{2}{*}{ Syringic acid } \\
\cline { 3 - 7 } \multicolumn{2}{|c|}{ Flow rate } & $0.9 \mathrm{~mL} / \mathrm{min}$ & 0.99 & 1.40 & 1.57 & 1.68 \\
\cline { 2 - 6 } & $1.1 \mathrm{~mL} / \mathrm{min}$ & 0.90 & 0.94 & 0.48 & 0.93 \\
\hline \multirow{2}{*}{ Temperature } & $27^{\circ} \mathrm{C}$ & 1.48 & 1.81 & 1.81 & 1.81 \\
\cline { 2 - 6 } & $29^{\circ} \mathrm{C}$ & 0.64 & 0.64 & 1.14 & 0.77 \\
\hline \multirow{2}{*}{$\begin{array}{l}\text { Detection } \\
\text { wavelength }\end{array}$} & $269 \mathrm{~nm}$ & 1.86 & 1.53 & 1.57 & 1.57 \\
\cline { 2 - 7 } & $271 \mathrm{~nm}$ & 1.50 & 1.95 & 1.97 & 1.63 \\
\hline
\end{tabular}




\section{Discussion:-}

In the present study, a novel HPLC method was developed and validated for quantification of Gallic acid, protocatechuic acid, vanillic acid and syringic acid in Phoenix dactylifera seeds. The study demonstrates that the method is specific, accurate, linear, precise and sensitive. The hydroalcohol extract of date seeds shows the presence of Gallic acid, protocatechuic acid, vanillic acid and syringic acid. All the compounds under investigation showed appreciable absorption at $270 \mathrm{~nm}$. The high value of R2 > 0.9906 in the tested range of $0.5-20 \mu \mathrm{g} / \mathrm{mL}$ concentrations is indicative of responsive linearity. The mean $\%$ recovery was found to be within the range, which indicates that the method is accurate. The standard analysis of the results proved that \% RSD of the peak areas obtained was $<2$; hence, the developed method was found to be precise. The low LOD and LOQ value indicates that the method is sensitive. The \% RSD was found to be within limits this ensured that the method is robust. The result reveals that protocatechuic acid is present in the highest amount in the hydroalcohol extract of Phoenix dactylifera seeds.

\section{Conclusion:-}

The present research work addresses the valorization of agricultural waste of date fruits. The enormous amount of date seeds which are thrown into the environment hold immense potential as raw material for bioprocessing and augmentation of new range of products. Date seeds are the cheapest source of phenolic acids and can be used as a source of herbal antioxidants. The developed HPLC technique is reported for the first time for the quantification of phenolic compounds in date seeds. The isocratic HPLC method resolve the compounds under investigation within a reasonable length of time. The results imply that the technique is selective and reproducible for the simultaneous quantification of phenolic compounds present in the date seeds. The present novel HPLC method will contribute to an accurate quantitative estimation of phenolic compounds in the date seeds which have not been quantified earlier.

\section{Acknowledgment:-}

The authors are thankful to the Oriental college of pharmacy, Sanpada, Navi Mumbai for providing required facilities for research.

\section{References:-}

1. Ateeq,A., Soni, D.S., Singh, K.V., Maurya, K.S. (2013): Phoenix dactylifera Linn. (pindkharjura): a review. Int J Res Ayurveda Pharm, 4 (3):447-451.

2. Choubey, S, Varughese, L.R., Kumar, V., Beniwal, V. (2015):Medicinal importance of gallic acid and its ester derivatives: a patent review. Pharm Pat Anal, 4(4):305-315.

3. ICH Harmonised, Tripartite Guideline Validation of Analytical Procedures: Text and Methodology Q2(R1),Geneva, 2005, 1-13.

4. Imeddedine, N., Sbih, H.M., Chin Ping Tan,Rashid, U.,Al-Resayes I. (2018): Chemical composition of date palm(Phoenix dactylifera L.) seed oil from six Saudi Arabian cultivators. J. of Food Sci, 83(3):624-630.

5. Itoh, A., Isoda, K.,Kondoh, M.,Kawase, M.,Kobayashi, M.,Tamesada, M., Yagi, K.(2009):Hepatoprotective effect of syringic acid and vanillic acid on concanavalin a-induced liver injury. Biol Pharm Bull, 32(7):12151219.

6. Joardder, M, Uddin, Md.S.U., Mohammad, N.I. (2015): The utilization of waste date seed as bio-oil and activated carbon by pyrolysis process Adv Mech Eng, 2012(4):1-6.

7. Kakkar, S., Bais, S. (2014): A review on protocatechuic acid and its pharmacological potential. ISRN Pharmacol, 2014:1-9.

8. Karizaki,V.M.(2017): Iranian dates and the ethnic date-based products. Journal of Ethnic Foods,4(3):204-209.

9. Mishra, R., Ahmed, R.(2016): Phytochemical analyais of seeds of Phoenix dactylifera. Int. J. Theor.Appl. Sci. Special Issue-NCRTAST, 8(1):156-160.

10. Parle, M., Khanna, D. (2010): Phytopharmacology of khajur (Phoenix dactylifera L.). Ann Pharm \& Pharm Sci, 1(2):109-115.

11. Srinivasan, S., Muthukumaran, J., Subramaniyam, R.V., Ramachandran, V., Muruganathan, U. (2013): Syringic acid, a novel natural phenolic acid, normalizes hyperglycemia with special reference to glycoprotein components in experimental diabetic rats. J Acute Dis, 2013: 304-309.

12. Tafti,G., Dahdiva,N.S.,Ardakani,Y.S.A. (2017):Physicochemical properties and applications of date seed and its oil. Int Food Res J, 24(4):1399-1406. 